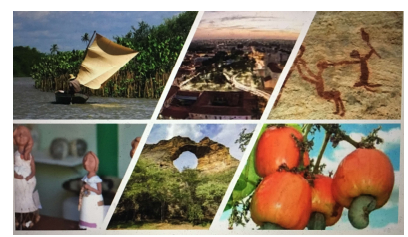

ISSN: 2675-1496 DOI: https://doi.org/10.26694/caedu.v1i2.9959

\title{
Entrevista com o professor Dr. Pablo Álvarez Domínguez
}

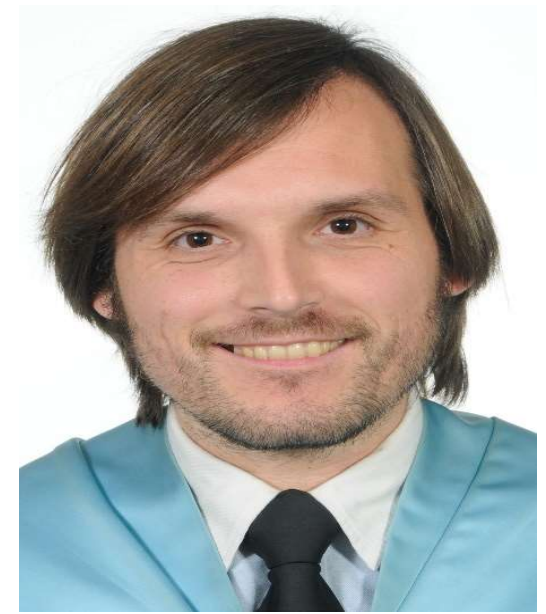

ENTREVISTA AL PROFESOR DR. PABLO ÁLVAREZ DOMÍNGUEZ FACULTAD DE CIENCIAS DE LA EDUCACIÓN. UNIVERSIDAD DE SEVILLA

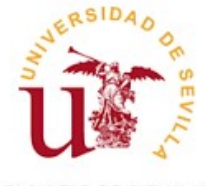

FACULTAD DE CIENCIAS DELA EDUCACIÓN

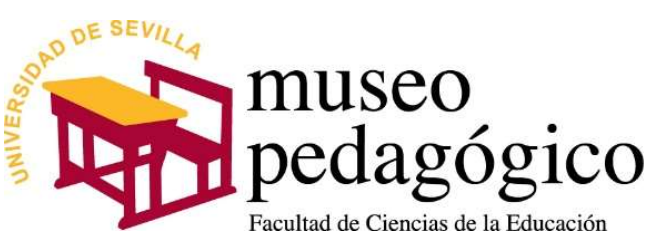

1-Profesor Pablo, ¿cuáles son los significados de estar entre los 10 educadores del año en España?

Los Premios EDUCA ABANCA a los Mejores Docentes de centros públicos y privados de España https://www.mundoeduca.org/premios-educa-mejor-docente-deespa $\% \mathrm{C} 3 \% \mathrm{~B} 1 \mathrm{a} /$, se convocan anualmente con el fin de reconocer públicamente la labor de aquellos/as profesores/as de Educación Infantil, Primaria, Secundaria, Formación Profesional y Universidad, que viven la educación activamente, se implican y disfrutan con su trabajo, se encargan de educar y enseñar para aprender a ser en la vida, y se involucran cada día con todo aquello que tiene que ver con el deseo de elevar el desarrollo de los procesos educativos al máximo exponente, tanto dentro como fuera del aula. Esta 


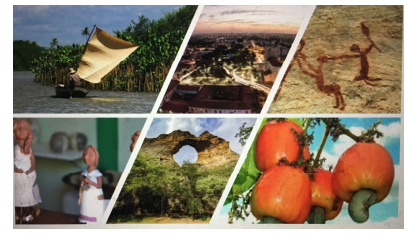

ISSN: 2675-1496 DOI: https://doi.org/10.26694/caedu.v1i2.9959

convocatoria, establecida como un referente educativo dentro de la sociedad española, tiene como objetivo reconocer el papel desempeñado por los mejores docentes durante todo el curso académico. De esta forma, se empeña por realzar socialmente la figura del buen docente, dignificando su papel en la sociedad actual. En cualquier caso, para mí lo más significativo de esta cuestión, quizás no resida en estar en este listado de finalistas, sino que lo más importante realmente, pienso que tiene que ver con el esfuerzo que se hace en sí por reconocer ante la sociedad, la existencia de profesorado comprometido con la mejora de la educación, la innovación pedagógica y el deseo de hacer del sistema educativo actual un instrumento de cambio y progreso social.

Y, puesto que es de bien nacido el ser agradecido, tal y como nos lo recuerda el inteligente refranero popular, es la palabra "gratitud" la que mejor puede expresar lo que ha significado para mí ser reconocido como uno de los 10 mejores docentes universitarios de mi país en 2019. Estar en este listado de privilegiados conlleva alegría máxima, satisfacción con el trabajo docente realizado día a día en silencio, y como no, felicidad al comprobar que tiene un sobresaliente sentido la cantidad de horas que dedico a repensar nuevas formar de educar para nuevos tiempos posmodernos. Sin embargo, y todo hay que decirlo, también supone una enorme responsabilidad, al tomar conciencia del efecto socioeducativa que puede llegar a tener mi particular quehacer docente. Suele decirse que el reconocimiento se alcanza cuando los resultados del trabajo que uno realiza llegan a ser valorados por agentes externos; no obstante, puedo asegurar que mi mayor satisfacción en esta ocasión reside en la capacidad que han tenido mis estudiantes para reconocer el modesto esfuerzo que cada día desarrollo en aras de sacar de ellos lo mejor que llevan dentro de cara a que algún día puedan convertirse en los mejores docentes del mundo. De esta forma, el aspirar a la excelencia docente, adquiere su máximo sentido en la medida en que contribuyo a dotar de conocimientos, herramientas, competencias y actitudes a los educadores del mañana.

No cabe duda de que la educación está experimentando en la actualidad un crítico debate mediático entre estamentos políticos, profesorado, alumnado y familias, en Revista Caminhos da Educação: diálogos, culturas e diversidades. CAEDU/UFPI 


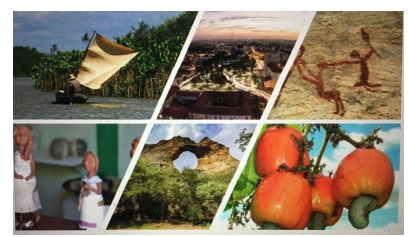

ISSN: 2675-1496 DOI: https://doi.org/10.26694/caedu.v1i2.9959

general. Y en esta línea, múltiples iniciativas docentes vienen implementándose por profesores/as de diferentes niveles educativos, que están contribuyendo a sentar distintos referentes pedagógicos individuales amparados en un modelo educativo que sale de los convencionalismos más tradicionales. Considerando lo cual, estos prestigiosos premios conocidos en España como los "Goya de la Educación", tratan de realzar la figura del buen docente y tienen como característica particular que ningún profesor/a se puede presentar individualmente, debiendo ser sus alumnos/as quienes los propongan en la primera fase del concurso. A este respecto, son mis estudiantes los protagonistas de mi didáctica; son ellos el motor que da rumbo a mi quehacer profesional.

En definitiva, recibir este reconocimiento social es una oportunidad excelente para confirmar que el trabajo docente que vengo haciendo está al menos a la altura de lo que espera una sociedad como la nuestra. Francisco de Quevedo (1580-1645), escritor español del Siglo de Oro, nos recuerda que el agradecimiento es la parte principal de un hombre de bien. Y en consecuencia, estar en esta ocasión entre los 10 mejores profesores universitarios de España es motivo de inmensa gratitud a la vida, que está siendo muy generosa conmigo.

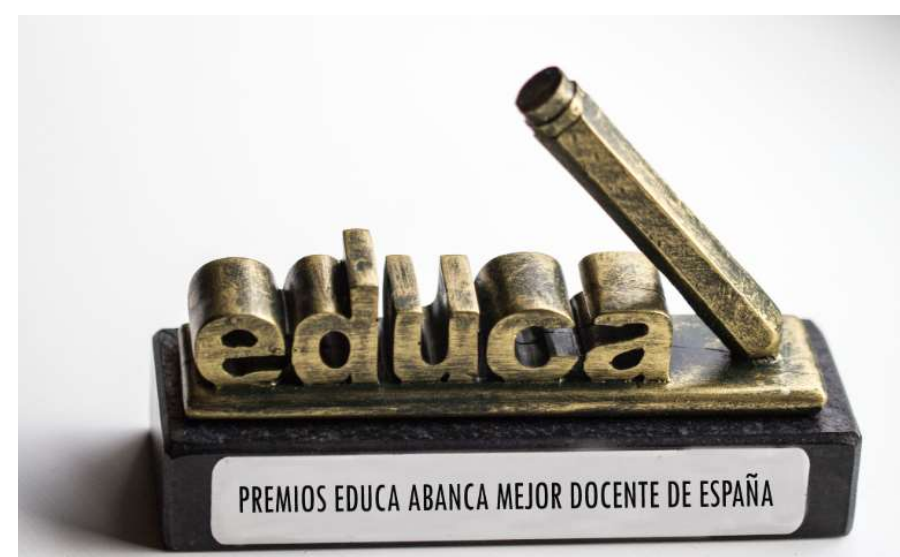

Imagen: Escultura. Premios Educa Abanca Mejor Docente de España. 


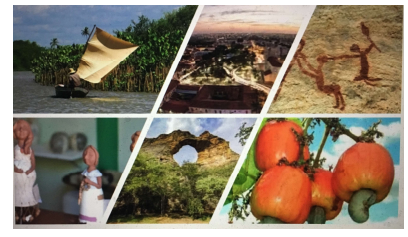

ISSN: 2675-1496 DOI: https://doi.org/10.26694/caedu.v1i2.9959

\section{2- ¿Usted podría contarnos un poco sobre sus prácticas de enseñanza y sus} inspiraciones?

Ni qué decir tiene que los/as profesores/as de Historia de la Educación tenemos un importante reto por delante en lo que atañe a la necesidad de adaptarnos a las nuevas maneras de enseñar que reclama la sociedad actual para los futuros educadores/as. Tenemos en nuestras manos la opción de que la docencia histórico educativa termine influyendo transversal y significativamente hablando en la formación de los maestros/as y profesores/as del mañana. Es precisamente este planteamiento el que me lleva a interiorizar la necesidad de innovar en la enseñanza de una disciplina como la Historia de la Educación. Todo ello, entendiendo la innovación como el encuentro de nuevos o mejores usos a los recursos de los que ya disponemos, en los términos señalados por Peter Drucker (1909-2005), tratadista austriaco considerado el mayor filósofo de la administración del siglo XX.

La presencia de lo atractivo supone siempre un valor fundamental en el ejercicio de la actividad docente, que repercute positivamente en los aprendizajes adquiridos por parte de los estudiantes. Por ello, participar en el reto de renovar la docencia universitaria desde la innovación y la creatividad, se presenta en este momento como una de las prioridades que dan sentido a mi quehacer profesional docente e investigador en la Universidad de Sevilla. Con esto, no estoy planteando exactamente un cambio radical de las prácticas docentes en la universidad, sino que más bien aspiro a mirar la educación desde una perspectiva diferente, más participativa, reflexiva, creativa y autocrítrica; lo que me lleva a impulsar una actuación pedagógica más basada en el mundo que nos rodea, es decir, más democrática, original, práctica, atractiva, artística, global, emocional y sentimental.

La Institución Libre de Enseñanza (ILE), junto a la potente revolución ideológica de grandes pensadores docentes como Francisco Giner de los Ríos, Manuel Bartolomé Cossío, Santiago Ramón y Cajal o Miguel de Unamuno, nos recuerdan la importancia de Revista Caminhos da Educação: diálogos, culturas e diversidades. CAEDU/UFPI 10

Teresina, Brasil, v. 1, n. 2, p. 7-20, maio/agosto de 2019.

ISSN: 2675-1496 DOI: https://doi.org/10.26694/caedu.v1i2.9959 


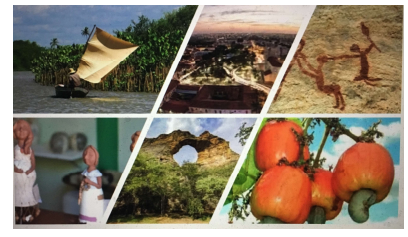

ISSN: 2675-1496 DOI: https://doi.org/10.26694/caedu.v1i2.9959

tomar en consideración algunas cuestiones fundamentales en relación con la docencia universitaria, tales como: a) la cercanía del profesorado; b) la impartición de la materia en círculos concéntricos; c) la intervención y la participación del estudiantado; d) la organización de los materiales y recursos; e) la inspiración creativa del docente en el aula; etc. En esta línea, he tratado de entender que nada es más nocivo para la creatividad que el furor de la inspiración, como apuntara Umberto Eco. Y precisamente, al hilo de este asunto, Erich Fromm nos recordaba que la creatividad requiere siempre tener el valor de desprenderse de las certezas. Hoy, entiendo que no podemos seguir asumiendo que a lo que habitualmente hacemos en nuestras aulas, nada creativo se le puede añadir. La actividad creativa es un tipo de proceso de aprendizaje en el que el profesor y el alumno se hallan en el mismo individuo.

En este momento, amparado en la poesía experimental como paradigma pedagógico artístico interpretativo, asumo que mi docencia histórico educativa se ha dejado seducir por nuevas teorías y discursos pedagógicos, en los que la historia y la memoria se han visto enriquecidas con las posibilidades pedagógicas de nuevas visiones, imágenes, representaciones, construcciones, etc., ligadas al desarrollo de un lenguaje visual que se enriquece con la aplicación de una pedagogía de las manos que tiene que ver con la construcción manual de ideas y pensamientos histórico educativos. Hacer poesía experimental supone someterse al desarrollo y expresión de una manifestación artística de carácter crítico interpretativo. Y esto conlleva contemplar la realidad histórico educativa para poder comprenderla; observarla para posteriormente interpretarla, y leerla para finalmente interiorizarla y representarla. La poesía experimental es una manifestación expresiva de carácter libre donde el arte se democratiza y se materializa. Toda creación es aprendizaje, y hacer poesía experimental es ejecutar un pensamiento a través de una creativa expresión de una idea y un mensaje. Mi didáctica actualmente no puede entenderse sin concebir la necesidad de transformar el pensamiento concreto en abstracto, encontrando oportunidades para hacer de lo cotidiano algo extraordinario, de lo convencional algo novedoso, de lo local algo global. Y, en esta ocasión, siendo Revista Caminhos da Educação: diálogos, culturas e diversidades. CAEDU/UFPI 


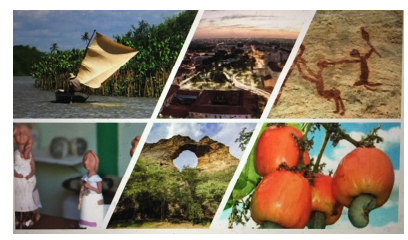

ISSN: 2675-1496 DOI: https://doi.org/10.26694/caedu.v1i2.9959

consciente de que la poesía experimental es un género iconoclasta destinado a romper actitudes convencionales en el arte, la concibo como un novedoso recurso didáctico para la docencia universitaria en lo que atañe a la enseñanza de la Historia de la Educación.

Actualmente, concibo mi docencia como una oportunidad para ayudar a viajar a mis estudiantes a través de la Historia de la Educación. Y para ello, les sugiero trabajar disruptivamente con maletas pedagógicas. El alumnado tiene encomendada la labor de configurar y crear manualmente un equipaje histórico educativo atendiendo a las orientaciones del profesor, y posteriormente ha de dar cuenta del mismo a través de representaciones teatrales, poniendo de manifiesto lo que se ha aprendido a través de la fabricación de estos objetos pedagógicos descontextualizados. Quizás algunas imágenes relacionadas con el trabajo didáctico que desarrollo, puedan ayudar a entender mejor mi particular manera de pensar y sentir los procesos de enseñanza aprendizaje que me corresponden coordinar e inspirar: https://www.youtube.com/watch?v=fFUvGO8amr0\&t=67s

He tratado de esbozar algunas ideas y pautas en las que me apoyo para dotar de sentido a mi actual planteamiento didáctico en la enseñanza aprendizaje de la Historia de la Educación. Sin embargo, soy consciente de que la limitación del espacio impide un mayor desarrollo de mi propuesta pedagógica. Si el lector quedara seducido o interesado por estas ideas, siempre tiene la opción de acudir a algunas de mis publicaciones sobre este tema. 


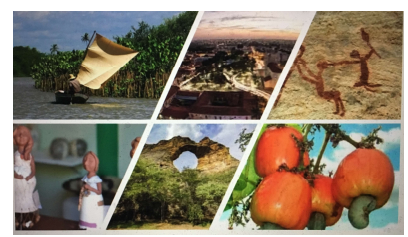

ISSN: 2675-1496 DOI: https://doi.org/10.26694/caedu.v1i2.9959

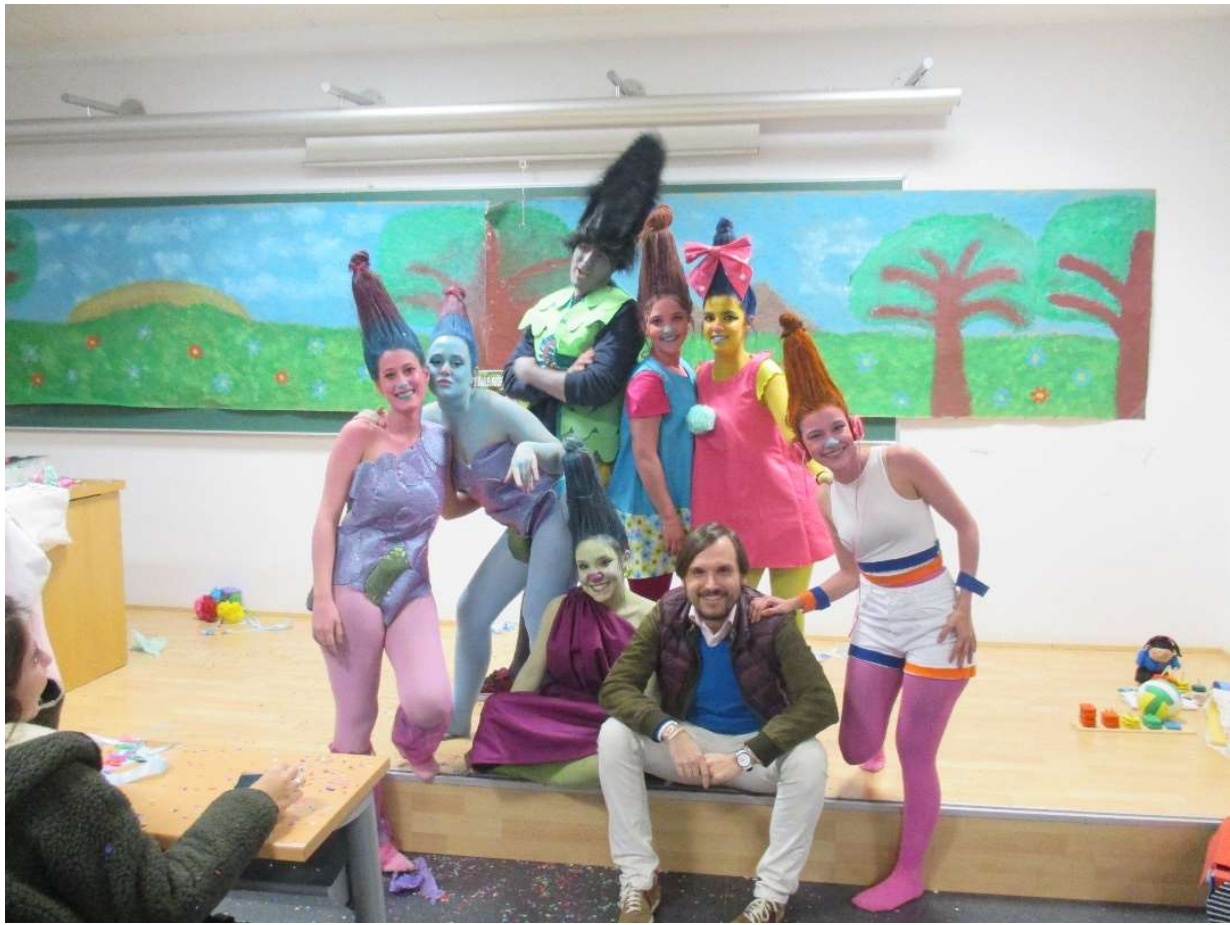

Imagen: Representación teatral. Estudiantes de Magisterio del Profesor Pablo Álvarez

Domínguez. Curso académico: 2017-18.

3- ¿Podría señalarnos 4 lecturas fundamentales en la formación de jóvenes educadores?

Para responder a esta pregunta, estoy convencido de que existen tantas respuestas como obras interesantes, que bien merecerían aparecer recogidas en esta ocasión a modo de sugerencia. Por ello, seleccionar solamente 4 lecturas ligadas a enriquecer la formación de los futuros docentes no es tarea fácil. El pedagogo estadounidense Amos Bronson Alcott (1799-1888), nos recuerda que un buen libro es aquel que se abre con expectación y se cierra con provecho. Y esta vez, valiéndome de una sugerencia tan acertada, me atreveré a señalar algunos títulos, tal vez no del todo convencionales, pero que entiendo que son capaces de captar significativamente el interés de los jóvenes que aspiran a ser docentes. 


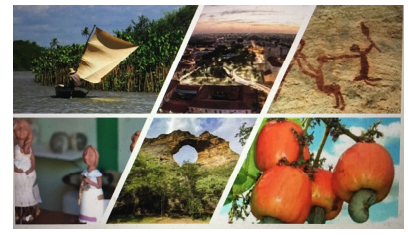

ISSN: 2675-1496 DOI: https://doi.org/10.26694/caedu.v1i2.9959

En primer lugar, y sin que este orden sea intencionado, me gustaría señalar la obra de de Frank McCourt, El Profesor (2006), que es una novela sobre la vida de un ingenioso profesor en Nueva York, que nos transmite una auténtica lección de humanidad. Si necesitamos nuevos docentes, claro está que precisamos de profesorado rico en humanidad. La obra nos narra la crónica sobre los desafíos a los que debió enfrentarse este profesor en un Instituto de Secundaria de Nueva York durante treinta años. Comienza el relato cuando McCourt tiene 27 años e inicia una actividad académica para la cual sus estudios en la Universidad no han acabado de formarle. En efecto, las realidades sociales en un entorno tan duro como el neoyorquino resultan difíciles de digerir por parte de este inmigrante irlandés. El profesor consigue despertar el interés de su alumnado desarrollando una pedagogía de la intuición, que le viene dictada más que por las directrices académicas, por su propia conciencia. Un buen día opta por bajarse de la tarima en la que viven instalados la mayoría de profesores/as y se dedica a escuchar a sus estudiantes y a aprender de ellos, poniéndose a su nivel para conocer sus necesidades, sus preguntas, sus inquietudes, sus preferencias y su forma de interpretar el mundo que le rodea.

En segundo lugar, quiero traer a colación la obra de Josefina Aldecoa, Historia de una maestra (2003), una narración plateada desde el recuerdo, llena de emociones y de sentimientos auténticos. En el año 1923 Gabriela recoge su título de maestra. Momento en el que comienza a trazar un sueño que la llevará a trabajar en varias escuelas rurales en España y en Guinea Ecuatorial. Historia de una maestra, con el trasfondo de la República, la Revolución de Octubre y la Guerra Civil Española, es una novela que rememora una época de pobreza, ignorancia y opresión, mostrando el importante papel de la enseñanza y de aquellos que lucharon por educar por encima de todo. En este libro, la autora nos traza un horizonte educativo de ilusión, esperanza e idealismo, atreviéndose a poner de manifiesto sentimientos y contradicciones que apenas nos atrevemos a reconocer normalmente cuando hablamos sobre temas educativos. 


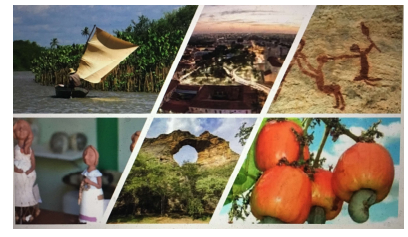

ISSN: 2675-1496 DOI: https://doi.org/10.26694/caedu.v1i2.9959

En tercer lugar, quisiera poner en valor la obra de Mariano Fernández Enguita, La escuela a examen: un análisis sociologico para educadores y otras personas interesadas (2004). Se trata de un libro que recorre con una mirada crítica los principales aspectos de la institución escolar, desde sus relaciones con la sociedad global hasta los procesos concretos en su interior. Así, las relaciones escuela-sociedad se analizan en sus dimensiones políticas (ciudadanía), económicas (trabajo) y de control (custodia de la infancia). Además, se estudia en detalle el sistema educativo español y su relación con el empleo. La obra presta especial atención a las desigualdades ante la educación, sean de clase, de género o étnicas, discutiendo las políticas con las que se ha pretendido afrontarlas. El libro termina adentrándose en la vida interna de los centros para estudiar tanto sus rutinas cotidianas, como el papel y las actitudes de profesorado, familias y estudiantes.

Y en cuarto lugar, en mi tónica pedagógica disruptiva, voy a apostar por traer a colación y sugerir la obra de María Acaso, rEDUvolution. Hacer la revolución en la educación (2013), en la que la autora propone iniciar en la era pedagógica actual una \#rEDUvolution, concebida como una revolución educativa circunscrita a cinco ejes básicos que tienen que ver con: aceptar que lo que enseñamos no es lo que los estudiantes aprenden; cambiar las dinámicas de poder; habitar el aula; pasar del simulacro a la experiencia; y dejar de evaluar para pasar a investigar. La obra plantea que el modelo educativo tradicional necesita adaptarse a las nuevas necesidades de los estudiantes, y para ello, propone un cambio de paradigma en la educación, que tiene que comenzar por preguntarnos qué es importante aprender y cómo hay que hacerlo. Si alguna idea fundamental nos transmite este libro, esta tiene que ver con que el aprendizaje sucede cuando el profesorado no solo pone la energía en lo que transmite, sino también en las aulas concebidas como espacios físicos en los que tiene lugar la transmisión de conocimiento.

La Pedagogía del Oprimido, de Paulo Freire, o incluso La alegría de enseñar, de Rubem Alves, son obras que también podrían incluirse perfectamente en esta precipitada Revista Caminhos da Educação: diálogos, culturas e diversidades. CAEDU/UFPI 


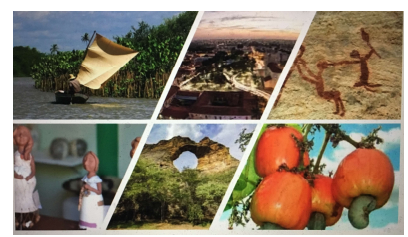

ISSN: 2675-1496 DOI: https://doi.org/10.26694/caedu.v1i2.9959

sugerencia. Amén de otros tantos títulos que en esta ocasión tengo que omitir por razones obvias.
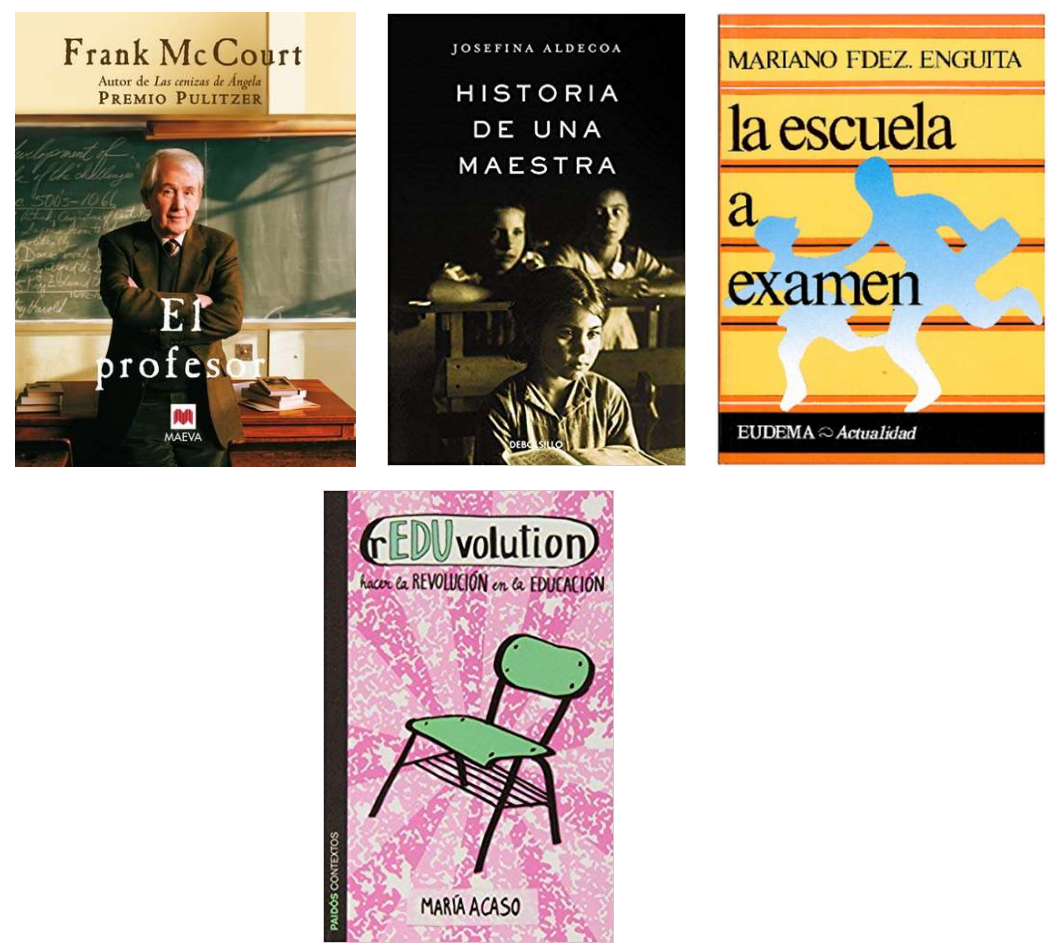

Imágenes: Portadas de obras pedagógicas para la formación de jóvenes educadores.

4- ¿Cómo fue la reciente visita que hiciste al Brasil? ¿Cómo nuestras realidades educativas pueden dialogar?

"Cuando conocí la tierra con la que yo quería trabajar, le puse la mano encima y enseguida me di cuenta por el oído, que me decía que era posible hacer mi obra con ella".

(Eduardo Chillida, 1924-2002). 


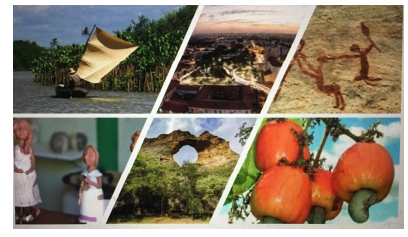

ISSN: 2675-1496 DOI: https://doi.org/10.26694/caedu.v1i2.9959

Brasil ha sido y es para mí puerta y ventana que me ha permitido descubrir y acceder a un mundo extraordinario en el que es un privilegio integrarse e incluirse. Brasil, todo él, y sus Universidades y sus amables gentes, en particular, forman parte de mi presente y de mi futuro. Parafraseando a Chillida, ha sido un placer abrir el oído para escuchar a Brasil y percatarme a la vez de las posibilidades educativas que su entorno me brinda. Recuerdo felizmente ahora cuando hace ya algunos años, la profesora M. Cristina Menezes, de UNICAMP, me cursaba invitación para realizar mi primera estancia de investigación en esa querida y respetada Universidad. Así, después de varios viajes a tierras brasileñas, el pasado mes de septiembre de 2019, tuve la suerte de nuevo de embarcar rumbo a Río, como lo hiciera en su cuarta película la actriz y cantante española Marisol, para pernoctar esta vez en la Universidade do Estado do Rio de Janeiro, aceptando la invitación que me hiciera la profesora Maria Celi Chaves Vasconcelos en el marco del Programa Capes Print, destinado a la promoción de intercambios de movilidad, estancias de investigación y proyectos conjuntos entre entidades de educación superior brasileña y de otros países. Mis días en tan apetecible y atractiva ciudad, fueron muy agradables, intensos en experiencias y emociones, y bastante productivos académicamente hablando. Confío en que mi quehacer personal en esta Universidad, contribuyera positivamente al enriquecimiento institucional de la UERJ, y al personal de cuantas gentes (profesorado y estudiantes, principalmente), pudieron compartir conmigo teorías, ideas, reflexiones y proyectos de futuro. El siguiente vídeo da muestra modesta y resumidamente de mi actuación en esta visita a Rio de Janeiro: https://www.youtube.com/watch?v=ZrU8-mpPQkY\&t=1472s

A continuación, habiendo tratado de responder muy sucintamente a la primera parte de la pregunta, paso a centrarme en la segunda. Soy consciente de que la comunicación es una necesidad de todo ser humano, y en consecuencia, requerimos los unos de los otros para vivir y adaptarnos a nuestro entorno, pues en definitiva, somos seres sociales en continuo proceso de formación y aprendizaje. Es la comunicación la que 


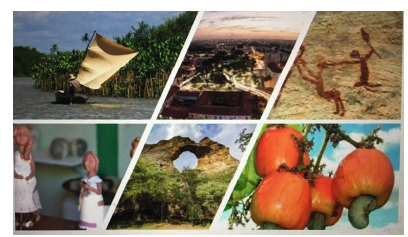

ISSN: 2675-1496 DOI: https://doi.org/10.26694/caedu.v1i2.9959

nos permite expresar al otro nuestros conocimientos, experiencias, ideas, intereses, necesidades, emociones y sentimientos.

Señala el diccionario que dialogar supone discutir sobre un asunto o sobre un problema con la intención de llegar a un acuerdo o de encontrar soluciones. Y a este respecto, ni qué decir tiene que en nuestras Facultades de Educación necesitamos diálogos interuniversitarios e internacionales entre realidades educativas diversas que aspiren a encontrar respuestas a tantas inquietudes y preguntas pedagógicas compartidas, que no entienden ni de los lugares que ocupan los países en el mapa, ni menos aún de idiomas distintos. En estos momentos, precisamos hallar oportunidades y relaciones entre la teoría y la realidad educativa, aprendiendo con y a través del diálogo y dialogando para aprender y poder enriquecernos mutuamente. Lo que está claro es que la suma de diálogos entre universidades internacionales es una sana práctica pedagógica que contribuye a aumentar la conciencia mundial acerca de la importancia de fraguar diálogos interculturales que aspiren a mejorar la atención a la diversidad, la inclusión, etc., posibilitando la necesaria transferencia del conocimiento a la sociedad. Solo a través del diálogo podremos mirar al pasado, para desde el presente construir juntos el futuro global de la educación.

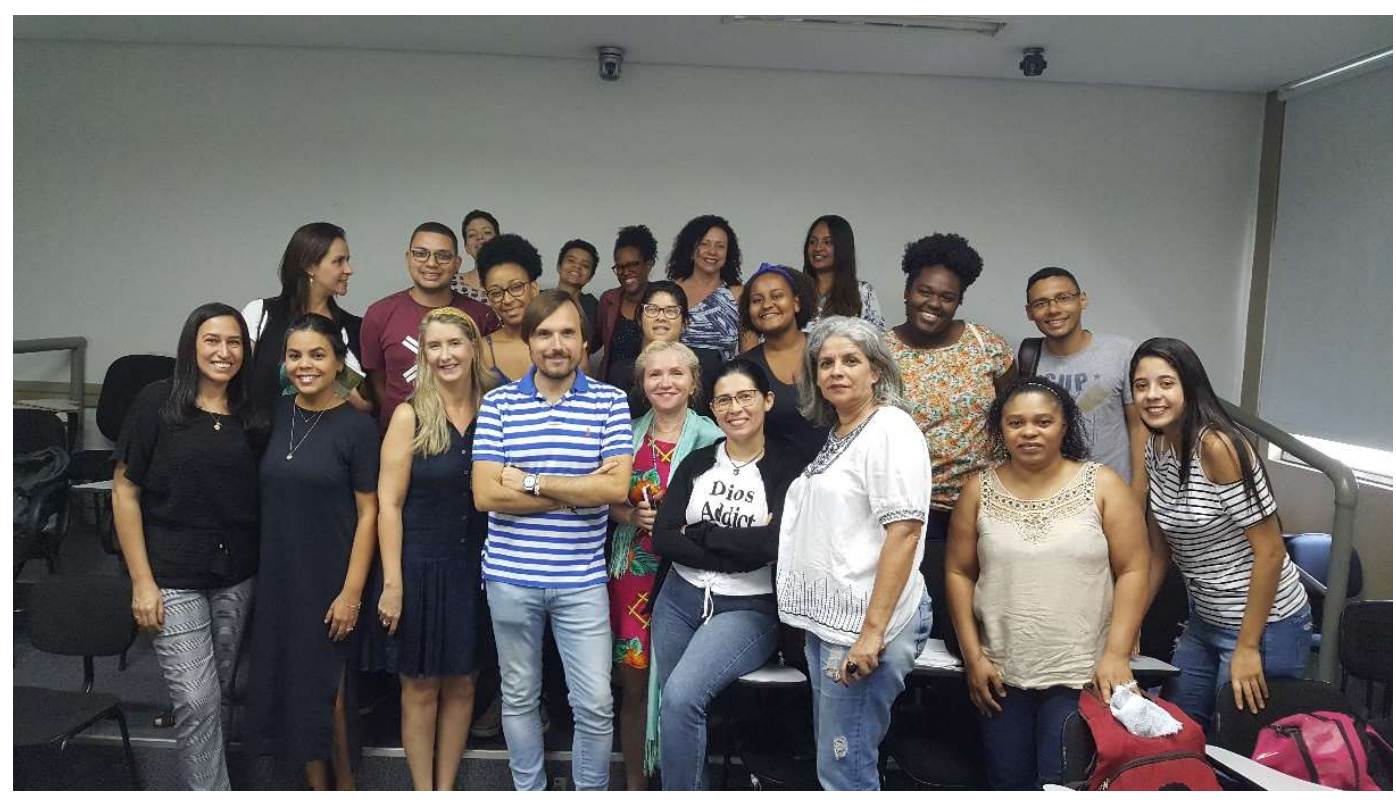

Revista Caminhos da Educação: diálogos, culturas e diversidades. CAEDU/UFPI

Teresina, Brasil, v. 1, n. 2, p. 7-20, maio/agosto de 2019. ISSN: 2675-1496 DOI: https://doi.org/10.26694/caedu.v1i2.9959 


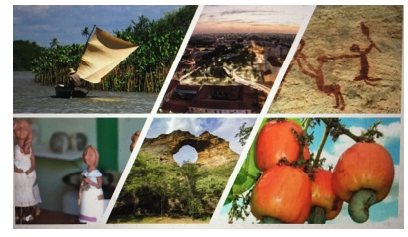

ISSN: 2675-1496 DOI: https://doi.org/10.26694/caedu.v1i2.9959

Imagen: El profesor Pablo Álvarez durante su estancia en la Universidade do Estado do Rio de Janeiro. Septiembre de 2019.

\section{5- ¿Cuáles son los desafíos de los historiadores de la educación en el tiempo presente?}

Partiendo de que la Historia no es una ciencia totalmente acabada, es preciso señalar que la Historia de la Educación tiene que seguir reivindicando en el presente la necesidad de ocupar un importante lugar dentro de los estudios históricos y la historiografía, en general. Ante ello, si reconocemos que la Historia de la Educación se integra cada vez más en la historiografía general, esto significa que la primera debe permanecer atenta para poder captar las influencias provenientes de las discusiones teóricas que se vienen planteando en relación con los planteamientos epistemológicos y metodológicos de la Historia como disciplina de carácter científico. En este sentido, la asimilación y puesta en práctica de nuevas formas de hacer Historia de una manera más participativa, permitirá a la Historia de la Educación ganarse un mayor reconocimiento y una más noble aceptación como parte de las disciplinas históricas. Así, nos corresponde propiciar un diálogo entre el pasado, el presente y el futuro educativo, tratando de transitar hacia una Historia de la Educación que sea capaz de redescubrir las experiencias educativas de la gente, otorgándoseles un protagonismo especial en diálogo con nuestro presente.

Al historiador de la educación le corresponde asumir el reto de estudiar y explicar desde la perspectiva histórica, cómo se desarrolla en un sistema social el hecho educativo concebido como un subsistema interconectado con realidades diversas. De esta forma, hay que ser consciente de que han ido aumentando los estudios de carácter microhistórico, en los cuales han adquirido un cierto protagonismo las prácticas de la cultura escolar y la representación, interpretación y difusión del patrimonio educativo; el estudio del 


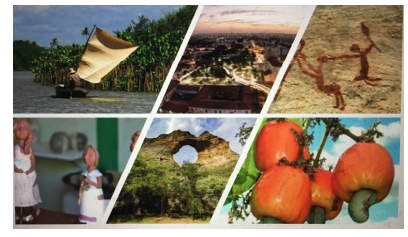

ISSN: 2675-1496 DOI: https://doi.org/10.26694/caedu.v1i2.9959

currículo y de las políticas educativas; el análisis de manuales, textos e imágenes utilizadas; el estudio de los actores y escenarios educativos; la recepción de los discursos educativos y los imaginarios en torno a la educación, por citar algunos ejemplos. Ante ello, es preciso insistir en que sigue y seguirá siendo necesario resaltar y redefinir la identidad del historiador de la educación, en aras de adquirir un papel fundamental en el estudio, análisis, recuperación, interpretación y explicación de una memoria colectiva que apremia ser descubierta, contada y puesta en valor.

Y al hilo de esta parte epistemológica, identitaria y hermenéutica de la Historia de la Educación -esbozada muy superficialmente-, otro de los desafíos actuales del historiador de la educación pasa por asumir un compromiso activo por colaborar en el desarrollo de competencias del alumnado universitario a través de una docencia histórico educativa amparada en el uso de nuevas metodologías docentes adaptadas a las necesidades que tienen en la actualidad los educadores del futuro. Participar activamente en el diseño y aplicación de procesos docentes innovadores en la enseñanza de la Historia de la Educación es un reto emergente de vital transcendencia e importancia, que contribuirá indudablemente a que la disciplina adquiera una nueva entidad e identidad que termine repercutiendo positivamente en la formación integral y transversal de los maestros/as y profesores/as del mañana.

Y consciente de que junto a estos desafíos también se encuentran otros tantos que por motivos de espacio se obviarán en esta ocasión, no me resisto a comentar - tal vez por deformación profesional-, que ante los actuales museos pedagógicos, de la educación y/o de la escuela, los historiadores de la educación tienen para con ellos un encomiable desafío por delante. La Historia de la Educación tiene que ser capaz de encontrar en estos museos pedagógicos la posibilidad de valerse de ellos como recursos investigadores y docentes que son, concebidos como espacios que, moviéndose a caballo entre la memoria del ayer y la creatividad a la que estamos convocados en la actualidad, participan activamente en la construcción de una nueva Historia material e inmaterial de la Educación. 


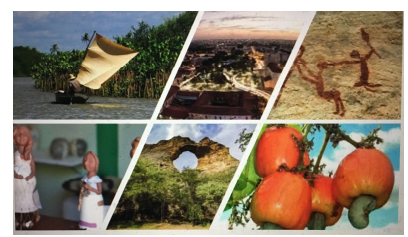

ISSN: 2675-1496 DOI: https://doi.org/10.26694/caedu.v1i2.9959

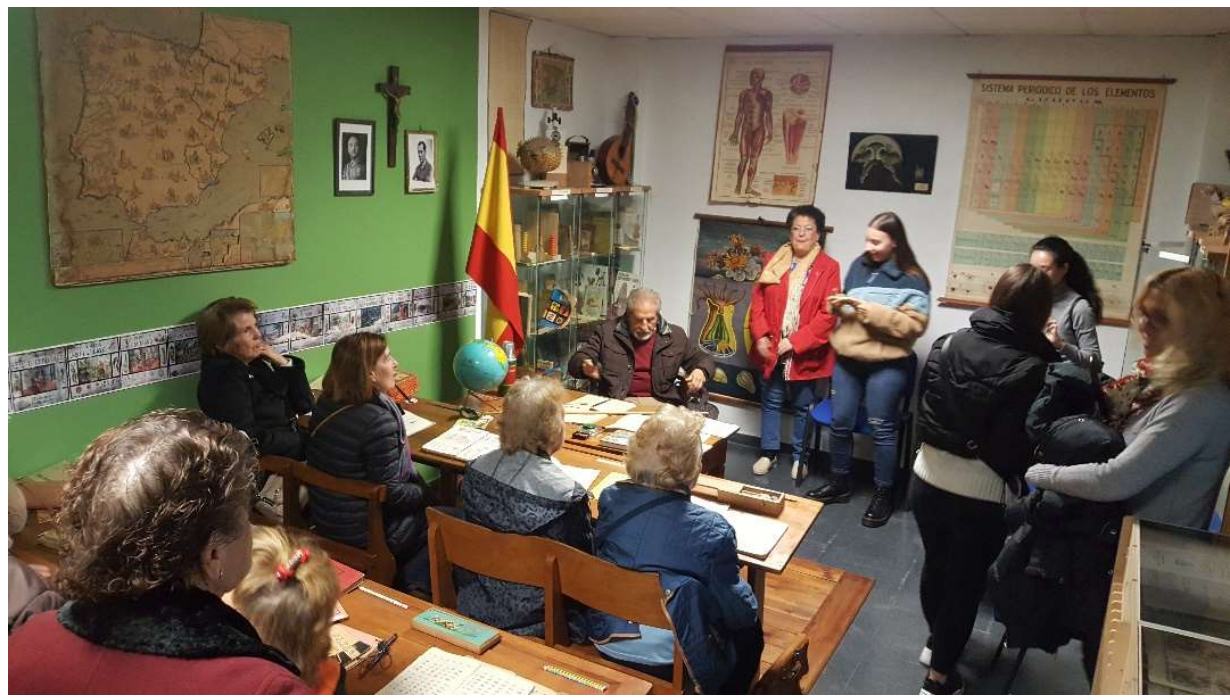

Imagen: Personas mayores visitan el Museo Pedagógico de la Facultad de CC. de la Educación de la Universidad de Sevilla (España), del que es secretario el Profesor Pablo Álvarez Domínguez. 